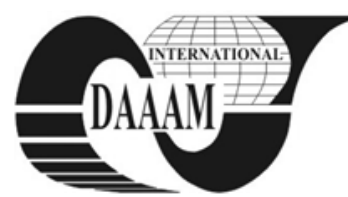

Annals of DAAAM for 2011 \& Proceedings of the 22nd International DAAAM Symposium, Volume 22, No. 1, ISSN 1726-9679 ISBN 978-3-901509-83-4, Editor B. Katalinic, Published by DAAAM International, Vienna, Austria, EU, 2011 Make Harmony between Technology and Nature, and Your Mind will Fly Free as a Bird Annals \& Proceedings of DAAAM International 2011

\title{
CONTRIBUTION ON ELECTROMAGNETIC SHIELDING OF WORKING AND LIVING SPACES
}

\author{
GUTT, G[heorghe]; GUTT, S[onia]; ALEXUC, F[lorin] - C[ristian]; STROE, S[ilviu] - G[abriel]; \\ MIRONEASA, S[ilvia] \& GUTT, A[ndrei]
}

\begin{abstract}
Screening systems that provides shielding of workspaces and living quarters of electromagnetic radiation in microwave and radio waves field from the environment are electrical structures presented in the paper. The energy of these radiations is consumed by means of passive resonant oscillating electric circuits, each provided at different wavelength and covering a wide range of frequency and by short-circuit copper or aluminum turns. Oscillating circuits and metal cage coils are invisibly embedded in various building or ornamental materials of spaces and uses the radiant energy from the outside by the resonant oscillation, turning it in heat and protecting living spaces effect of high frequency electromagnetic radiations.
\end{abstract}

Key words: electromagnetic rooms shielding, short-circuit turns, passive oscillating circuit

\section{INTRODUCTION}

Atermic effect of electromagnetic radiation, specifically to low-intensity emissions from mobile phones, radios, radar, etc. it is not directly measurable by heating the living bodies exposed, that is manifested by the degradation that can lead to tumor cell, last statement is currently certified by specialists(Abdel et al., 2006), (Hutter et al., 2006), (Fritze et al., 1997), (Finnie et al., 2002). Solutions that appeal to socalled Faraday cage are used for electromagnetic shielding which means dressing your living or working space in a metal shell, usually made of wire mesh form, bound to earth. Faraday cage isolated only low frequencies, has a high cost price and make aesthetic problems when it is done after finishing the building (Johannes et.al., 1992). Currently, for high frequency electromagnetic shielding technical means are applied to building achievement, or correctly applied without structural changes in buildings. The concern of the authors (Gutt et. al., 2010), (Gutt et.al., 2010-1), (Gutt et.al., 2010-2), is the achievement of performance electromagnetic shielding means with the primary purpose of these insulated structures to be passive, to screen a high range of frequencies from the environment, to be applied easily in terms of technology and to provide a low cost.

\section{EXPERIMENTAL}

In the first phase of research were developed means of electromagnetic shielding with primary materials destination for construction having the aim of neutralizing the highfrequency electromagnetic radiation by using shorting rings of copper sheet, of various diameters, the rings being more evenly distributed in building materials brick displacement type, concrete blocks, concrete, or material of gypsum boards flat type, fibreboards, fibreboards plated with plastics or veneer being used in the construction and / or plating rooms and furniture manufacturing. High-frequency radiation from the environment are processed by copper rings in heat by eddy currents and inductive heating, these rings being in fact some electrical turns in short-circuit, they can be made of copper sheet by punching, thin copper tubing having various outer diameters, using automatic laser cutting, or copper wire with automatically bonding of wound heads.

In Figure 1, a, b, c, d, e, are presented these solutions.

In the second phase have been developed corrective means for living and working spaces so that they do not affect the environment on the contrary help to harmonize it.

Passive LC oscillating circuit are the basic constructive elements in this case (Figure 4), made from thin sheets of aluminum foil glued to a polyethylene support figure 2, bands that are embedded during the manufacturing process within building material type of gypsum boards, fiber boards, plasticfaced hardboards, etc., used later in the realization of buildings, plating inhabited rooms, or performing furniture. Oscillating circuits consumed radiant energy from the external environment and convert it into heat protecting living space by its electromagnetic shielding in a wide range of specific frequency of environment electromagnetic radiation.
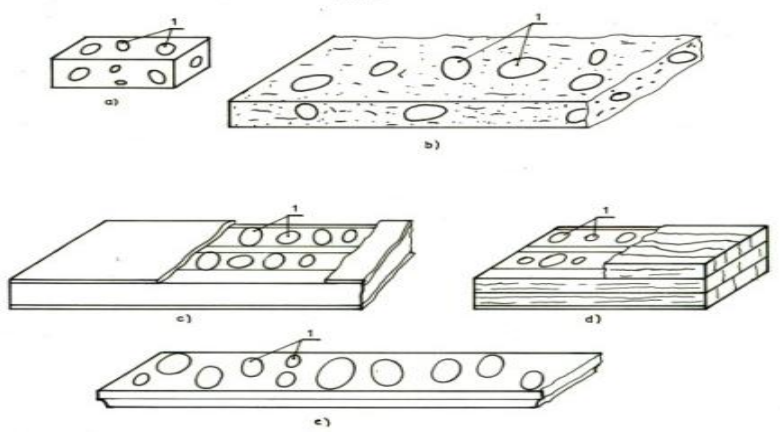

Fig.1. The solution for incorporation of copper rings in various primary building materials such as (a), bricks, (b), fibrous wood plates, (c) veneered or coated with melamine plates, (d), laminated wood, (s) gypsum boards.

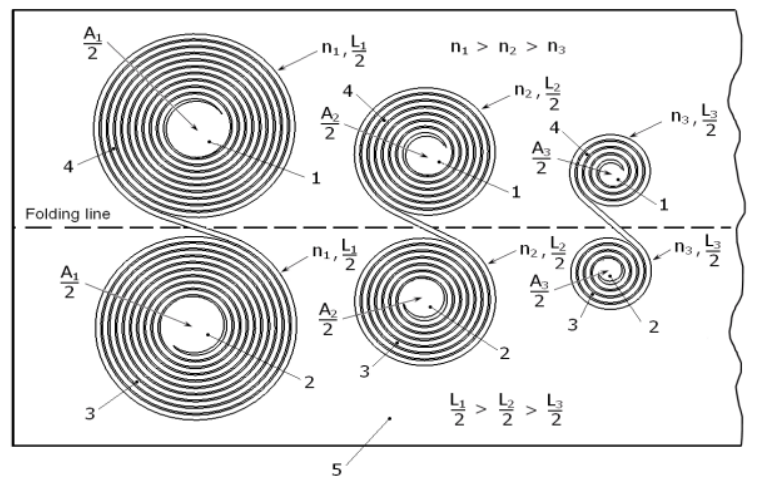

Fig.2. The view in the mirror of a strip segment of oscillating circuits containing three inductors and three identical capacitor plates, glued on polyethylene film, in final resulting by symmetrical folding three oscillating circuits, symmetric three oscillating circuits, each tuned to different resonant frequency. 

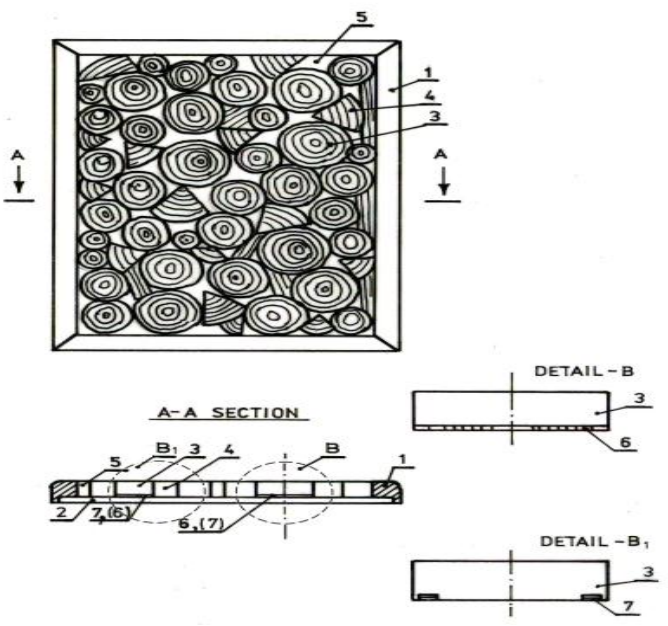

Fig. 3. Decorative panel with electromagnetic shielding role achieved with passive oscillating circuit of copper coils in cage: 1-wood-frame, 2-base plate, 3- disks of equal thickness resinous branches but different diameters, 4-segment for filling gaps, 5-glassy and transparent synthetic filling resin, 6oscillating plane circuit type LC, 7-copper rings of different diameters connected in short-circuit

A special solution is to fit such a kind of oscillating circuits, figure 2 (see detail B1-fig.3) and of copper coils in the circuit of the type shown in Figure 1 (see detail B Fig.3), behind of some discs made from resins branches, discs that are then glued on flat substrates, realizing ornamental panels with advanced electromagnetic shielding, but with a soothing effect by geometric aesthetic obtained.

\section{RESULTS AND DISCUSSION}

Making electromagnetic shielding promoted by the authors is based on electromagnetic radiation consumption at low and medium frequency, through a large number of copper turns cages placed in various construction materials, Figure 1, and at the high frequency oscillating circuits placed passive, figure 4, between environment and living space, using for this purpose LC oscillators with resonance frequencies given by different specific frequencies (telephone, radio, radar, etc.) existing in the environment to calculate the resonant frequency $\mathrm{f}_{0}$ or circular frequency (angular velocity) $\omega_{0}$ of LC oscillator circuit is used Thomson's relationship

$$
f_{0}=\frac{1}{2 \pi \sqrt{L C}}
$$

where:

$$
\begin{aligned}
& \text { L - inductance coil } \\
& \text { C - condenser capacity }
\end{aligned}
$$

Radiant energy absorbed by the oscillating circuits embedded in the structure of various building materials is consumed by the coil plane resistivity and by dielectric loss of plan capacitor being converted into heat. A way to achieve an oscillating circuit bands, which have different resonant frequency given to the specific frequency values existing in the environment is the use of the aluminum foil glued on a thin polyethylene strips. In order to generate chemical the coil and the plan capacitor, aluminum foil is coated with a photoresist polymer, then irradiated with ultraviolet radiation through a mask which reproduces on scale the image of coils and the armature of capacitors. After this operation, follows a chemical film development the which 1 have the effect of dissolving both the polymer as well as the aluminum foil in irradiated area, on polyethylene strip remaining two half $L C$ oscillating circuits in mirror, the two coils being in the form of two identical plane

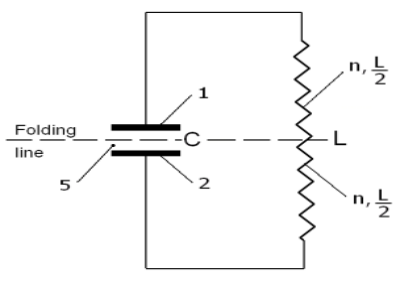

Fig. 4. Schematic diagram of the L-C oscillator: 1, 2-plates, 2dielectric $(2 \mathrm{x}$ thickness of plastic film), n-number of coil turns

spirals, the Archimedean spirals, each of them having a disc in the center which is an armature of the oscillating circuit capacitor, figure 2. Oscillating circuit is functional only after folding the polythene foil on a line of symmetry which passes through coils pairs and pairs of capacitor armatures. Total coil inductance $L$ consists of the sum of two inductances $L / 2$ of the two symmetric coils, and capacity $C$ of the capacitor is given by the two capacitor armatures that have as dielectric a double polyethylene foil between them. A strip contains, depending on its length, up to tens of $L C$ oscillating circuit each having the resonant frequency given on another representative value by proper sizing of the surface area A of capacitor armatures and by the number of coil turns. Mechanical stamping followed by folding is another way to achieve oscillating circuits.

\section{CONCLUSIONS}

The achievements of the team in the field of conception and design of means for varied shielding field provides an electromagnetic shielding in low-cost price conditions, in a large range of frequencies existing in the environment, thereby protecting the living and working spaces of harmful influence of electromagnetic radiation of low and high frequency. Electromagnetic shielding system developed does not require power supply, maintenance and control to be operating throughout the duration of the building, throughout the duration of the plating room or using the furniture or ornamental structures type painting type.

\section{REFERENCES}

Abdel, R., El-Fateh, A., et al. (2006), Neuro Toxicology. 28, Nr. 2, New York, NY, pp. 434-440

Hutter, H.,P, Moshammer, H., Wallner, P., Kundi, M. (2006), The BMJ Publishing Group Occupational and Environmental Medicine. 63, Nr. 5, London, UK, May 1, pp. 307-313

Fritze, K., Sommer, C., Schmitz, B., Mies, G., Hossmann, K.A., Kiessling, M., Wiessner, C. (1997), Effect of global system for mobile communication (GSM) microwave exposure on blood-brain barrier permeability in rat, Acta Neuropathol 94, pp. 465-470

Finnie, J.W., Blumberg, P.C., Manavis, J., Utteridge, D., Gebski, V., Davies, R.A., Vernon-Roberts, B., Kuchel, T.R. (2002) Effect of long-term mobile communication microwave exposure on vascular permeability in mouse brain, Pathology 34, pp. 344-347

Johannes, W., et al. (1992) Elektromagnetische Verträglichkeit , 5. Auflage, Expert Verlag, Ehningen bei Böblingen, p.372

Gutt, G., Gutt, S., Alexuc, F., C., (2010) Building materials for electromagnetic shielding of rooms, Patent proposals A/00157, (romanian), OSIM Bucuresti

Gutt, G., Gutt, S., Stroe, S., Alexuc F., C., (2010-1) Rooms electromagnetic shielding process, Patent proposals A/00158, (romanian), OSIM Bucuresti

Gutt, G., Gutt, S., Gutt, A., (2010-2), Panel for electromagnetic shielding of rooms, , Patent proposals A/00553, (romanian) , OSIM Bucuresti 